\title{
Configurações
}

Revista de sociologia

$9 \mid 2012$

Trabalho e género: vidas precárias, percursos e acção colectiva

\section{Exceder os limites: a crítica feminista contemporânea na obra de Ana Bê}

To exceed the limits: the contemporary feminist critics in the work of Ana B.

Pereira

Dépasser les limites : la critique féministe contemporaine dans l'oeuvre d'Ana B̂̂

Lennita Oliveira Ruggi e Rosimeire Barboza Silva

\section{(2) OpenEdition \\ Journals}

Edição electrónica

URL: http://journals.openedition.org/configuracoes/1169

DOI: 10.4000/configuracoes. 1169

ISSN: 2182-7419

Editora

Centro de Investigação em Ciências Sociais

\section{Edição impressa}

Data de publição: 30 Junho 2012

Paginação: 161-180

ISSN: 1646-5075

\section{Refêrencia eletrónica}

Lennita Oliveira Ruggi e Rosimeire Barboza Silva, «Exceder os limites: a crítica feminista contemporânea na obra de Ana Bê », Configurações [Online], 9 | 2012, posto online no dia 27 novembro 2013, consultado o 02 maio 2019. URL : http://journals.openedition.org/configuracoes/1169 ; DOI : 10.4000/configuracoes. 1169

Este documento foi criado de forma automática no dia 2 Maio 2019.

(c) CICS 


\title{
Exceder os limites: a crítica feminista contemporânea na obra de Ana Bê
}

To exceed the limits: the contemporary feminist critics in the work of Ana B.

Pereira

Dépasser les limites : la critique féministe contemporaine dans l'oeuvre d'Ana Bê

Lennita Oliveira Ruggi and Rosimeire Barboza Silva

\section{Prólogo}

\author{
a oportunidadE privA a teoriA \\ SER penteando as mães as putas \\ as mães que engolem as putas \\ as putas que vomitam as mães \\ as mães que rasgam as putas \\ as putas que se salvam das mães \\ e PRINCIPALMENTE o homem-todo-alicerce \\ que as nomeou rotulando na \\ mera ejaculação de armários onde \\ pudesse depor os pés \\ garras construídas sobre o pó \\ o en carne ser mirrado sustendo dinamismos
}

Convulsa, abrangente, sem concessões: "as mães que engolem as putas/ as putas que vomitam as mães" (Pereira, 2007: 14). Incômoda. "A oportunidadE priva a teoriA/ SER penteando" remexendo e escavando lugares, redefinindo espaços matizados pela experiência corporéa "as putas que se salvam das mães", porque a vida em si não permite linearidades, nem tampouco respostas fáceis, antes, a palavra é uma forma de questionar significados amplamente visitados por mães e por putas, o lugar social da opressão, que as nomeia e coage, relegando-as, por meio de discursos-rótulos a um espaço subalterno e movediço onde, para se sobreviver, é necessário ter garras e lutar "sustendo dinamismos". 
2 Subverter os limites, para desvalidá-los: assim é Ana Bê, sua poética e escrita científica: sem meias palavras, o princípio é sempre o espaço que ocupa para dizer a que veio. A luta começa a ser travada no espaço de uma folha, antes mesmo de ela se converter em poesia, já que sua escrita é imagética e sensorial. Um exercício quase palpável, imediato, visceral.

3 Ana Bê, 36 anos, portuguesa, nascida no Distrito de Coimbra, é poeta, como faz questão de ser chamada (e não poetisa) e utiliza sua arte como uma forma de denúncia contra a estupidificação, contra o imobilismo e contra os inúmeros preconceitos enraizados no âmago de nossas práticas cotidianas, banais. Escreve, como diz, contra os "apagamentos, ocultamentos e invisibilidades" (Pereira, 2008). Poeta e militante feminista, lésbica e, pelos direitos das pessoas com deficiência, o currículo de Ana inclui a licenciatura em Letras inglês/alemão e o mestrado em Sociologia na linha de estudos de PósColonialismos e Cidadania Global, ambos pela Universidade de Coimbra. Actualmente é doutoranda na Universidade de Lancaster no Reino Unido. Dedicada a traduções para língua portuguesa, circula com familiaridade entre a literatura feminista de língua inglesa, tendo especial predileção pela obra da estadunisense Toni Morrison.

4 Jovem autora à margem do mercado editorial de grande porte, Ana Bê redimensiona a literatura engajada, conjugando a experimentação estética com o exame minucioso da inserção das mulheres na sociedade. Consciente das armadilhas misóginas implícitas nas línguas europeias modernas, esfacela as barreiras estabelecidas para reivindicar seu espaço de enunciação, simultaneamente pessoal e político, já que não seria possível divorciar as duas instâncias. A leitura paralela de suas duas principais obras permite aceder às sutilezas, inovações e desafios propostos.

5 Partimos, portanto, de sua coletânea de poemas intitulada "As patas posteriores das pulgas" (2007) e da dissertação de mestrado concluída em 2008: "Viagem ao interior da sombra: deficiência, doença crónica e invisibilidade em uma sociedade capacitista”, para tentar repensar os espaços que ocupamos, nossas concepções de corpo e experiência e a contribuição crítica dos feminismos, suas escritas, poéticas e suas lutas para a consolidação de um conhecimento realmente comprometido e emancipatório, que busca a liberdade, desestabilizando consensos e naturalizações, resignificando-os para além dos limites e das molduras.

\section{Excede(ndo)r a semântica das molduras ${ }^{1}$}

o tempo e suas altas construções de metal abrangentes toda a anatomia do sonho uma casca. casca ta de papel imprimindo-se um ritmo de unhas ao pescoço desliza dando-se era. (Pereira, 2007: 12).

6 Uma moldura é um limite. Uma espécie de cerca que fixa e circunscreve algo a determinado espaço. Por isso mesmo, uma moldura reduz e restringe dimensões, ideia que seria inconcebível para a poesia de Ana Bê: poesia que se quer possibilidade, subvertendo idéias e temporalidades, o EXCEDER as convenções torna-se exigência quando buscamos explorar os sentidos e sentires de que é feita sua luta, sua literatura.

7 Numa gramática ousada, que mistura texturas, sensações tácteis, antónimos e devires, Ana une materialidades (moldura) e discursos (semântica) no mesmo espaço, evocando-os integrados, para falar de tudo aquilo que nos restringe: exceder essa dinâmica das molduras é um convite provocador, claramente uma proposta para extrapolarmos o conhecido, o comum, o visível, o confortável e questionarmos espaços que estão para além das aparências. Ana brinca com as convenções, para desconvencioná-las. 
8 Aqui o desafi o é re-olhar o mundo por meio de suas fissuras para ampliá-lo. Revolver a camada de ensimesmamento que nos imobiliza para podermos tocar estruturas tão ambiciosas como "o tempo e suas altas construções de metal abrangentes [onde reside] toda a anatomia do sonho" (Pereira, 2007:12).

9 EXCEDER por isso mesmo é mandatório, uma forma de dizer que ultrapassar as aparências é ir em direção a um mundo ocultado, silenciado que, mesmo aparentemente nãoexistente ${ }^{2}$, é criado assim ativamente. Ana propõe um contínuo movimento, um dentrofora-dentro de nossas reflexões - "imprimindo-se um ritmo de unhas ao pescoço" - sejam elas literárias ou cidadãs. É nesse exercício de forçar os limites para além do imediatamente perscrutável que Ana situa seu livro: “as Patas Posteriores das Pulgas têm a ver exatamente com o que está de fora, o quê todas/os rejeitam, o quê ninguém vê, e também, com o quê a maioria das pessoas não consideraria poético ou de relevo", diz-nos.

Seu posicionamento situado e incorporado ${ }^{3}$, excede limites quando desoculta e deslinda exclusões. Como feminista que assume explicitamente seu lugar de enunciação, Ana Bê também situa o corpo material como lugar da luta política, que é seu corpo-voz-sujeitode-si-mesma/o:

Em primeiro lugar, como uma pessoa com deficiência que tem uma doença crónica não posso nem quero ter uma posição neutral face às questões que aqui abordo [refere-se à sua dissertação de mestrado]. A minha postura é eminentemente política no sentido em que pretendo advogar claramente os direitos das pessoas com deficiência e doença crónica. Este não será por isso um estudo influenciado por abordagens positivistas que defendem o distanciamento da investigadora relativamente ao assunto estudado. Do meu ponto de vista, não existe neutralidade possível face à opressão, à exclusão e à discriminação. Eu sei exactamente de que lado quero estar e qual a importância de por ele lutar (Pereira, 2008:16).

11 Escrita engajada e que se assume como tal, o EXCEDER aqui também funciona como uma espécie de prevenção contra as supostas neutralidades, desafiando posições que se arrogam não militantes, descomprometidas. Participante, durante muitos anos, da experiência intitulada como oficina de Poesia ${ }^{4}$, Ana Bê sofreu influências da escola $\mathrm{L}=\mathrm{A}=\mathrm{N}=\mathrm{G}=\mathrm{U}=\mathrm{A}=\mathrm{G}=\mathrm{E}$, criada nos Estados Unidos por Charles Bernstein, poeta e professor que defende explicitamente o caráter político e militante que sua escola desempenha no cenário poético mundial: "Fingir que não se é militante, que se está acima do combate, separando o «melhor» do "pior» sem «rancores ideológicos» - como dizia recentemente um poeta por sinal bem militante, afirmando a sua militância no ato de a negar - é uma forma, por demais recorrente, de mistificação e má-fé, que tem como objetivo reforçar a autoridade das nossas próprias afirmações" (Bernstein, 1997: 102).

Por meio dessa perspectiva política explícita, que funciona como antídoto contra a paralisia social e a arrogância individual, Ana Bê constrói uma poética-escritura que se realiza no corpo e por meio dele: dizer-se e saber-se é também uma forma de repensar-se e colocar-se para além dos limites, interiores e exteriores e, sobretudo, marcar presença no mundo, ocupar espaços, forjar diálogos "chamando poesia às fendas, excesso, às obstruções" (Bernstein, 1997: 110), propondo coletividade no ato mesmo de nomear-se a si em relação com outras/os. Esse exercício, que se traduz em atividade extenuante e colectiva, é também exigência histórico-material:

...é de extrema relevância dizermo-NOS. Se eu me digo deficiente e pessoa com doença crónica, eu preencho esse espaço no mundo. Eu passo a habitar uma espacialidade que torna essas características visíveis. O problema, naturalmente, é que nem sempre é fácil dizermo-nos. As pessoas com doenças crónicas vivem 
constantemente nesta angústia. É possível que sejam penalizadas por se dizerem e é possível que o oposto aconteça, como o meu trabalho de campo elucidou. A própria volatilidade e imprevisibilidade da doença coloca-as num espaço indefinido com o qual tanto elas como os outros têm dificuldade em lidar. 0 facto de vivermos numa sociedade habituada a suprimir qualquer conhecimento relacionado com a doença e que a vê exclusivamente a partir de um paradigma biomédico faz com que não tenhamos mecanismos efectivos de com ela nos relacionarmos (Pereira, 2008: 230).

Quando EXCEDE o visível, Ana amplia os limites de si, mas não só. Sabe que as delicadas estruturas que tecem as invisibilidades cotidianas, com as quais nos deparamos, é uma construção dinâmica e, por isso, somente poderemos des-tecê-las colectivamente. Quando se diz - note-se: é impossível dizer-se em singular, e por isso o sujeito de sua dissertação é colectivo - sublinha, "é de extrema relevância dizermo-NOS" (Pereira, 2008: 230), Ana sabe o quanto está implicada nesse processo, vencer as opressões é uma constante luta pela liberdade, pelo EXCEDER as bordas do que nos cerca constrangendo nossa ação no mundo e, essa implicação só se faz, por meio da integralidade. Ana, ocupa assim um espaço e por isso compreende que a liberdade é um caminho e não um estado: "uma prática que nos capacita a construir - coisa que só podemos fazer colectivamente compostos articulados e nesse sentido necessários, por sua vez compartilhados e desejados, cuja eficácia consista no aumento da potência de actuar colectivamente." (Galcerán, 2009: 109).

14 É a tessitura entre conhecimentos situados, corporificados e políticos que vai dando forma e aumentando essa potência de actuar colectivamente de que nos fala Galcerán (2009). Seu corpo-voz-sujeito e escrita conjugados fazem de Ana e sua corporalidade elemento fundamental na desconstrução de barreiras e molduras.

15 O EXCEDER, palavra que vai adquirindo amplos e novos significados nessa escrita é também um jogo maleável que se diz na multiplicidade, nos encontros e desencontros de um conhecimento corporificado-visceral, político, explícito e como não poderia deixar de ser: exercício solidário e colectivo que só é compreendido por meio de palavras como liberdade, um olhar além e para além das aparências que nos cerceiam e invisibilizam.

16 Ana, em suas escritas, se metamorfoseia em múltiplo exercício, experiencial, nunca definitivo. Seu corpo, uma articulação através dos limites e para além deles, fala, em si, de uma imensidade de corpos: "O problema, naturalmente, é que nem sempre é fácil dizermo-nos. As pessoas com doenças crónicas vivem constantemente nesta angústia" (Pereira, 2008: 230).

17 Nesse contexto a neutralidade é impossível e a liberdade necessária para a acção política, uma exigência premente. As subjectividades são corpos entrelaçados que entremeiam vivências. Ana não é apenas uma, fi que claro, mas sim uma multiplicidade de sentires, de sujeitos. O que também não é fácil, já que "é um desafio escolher o lugar desde onde podemos nos repensar sem cair na banalidade ou no refúgio categorizante" diz Maria Galindo, artista e feminista ${ }^{5}$.

18 Entretanto, para além da consciência, os sentidos do mundo são muito mais complexos e emaranhados, não basta apenas se "repensar", provoca Ana, é necessário ir lá, onde na bifurcação do corpo, aninha-se a dúvida, a angústia e o sentir se faz imperativo. Para além de subjectividades e agência, somos sujeitos nómadas, em constante mutação e convivemos todas e todos com o medo, a rejeição, com o que é impossível de ser só afirmação: 
essa sílaba colada à articulação do espaço na modificação do absurdo deste eclipsado passado medido pela língua da espinha. tornando-se a ficção daquela espera. não esperavas a ausência nem a bifurcação das sementes nem o semear das raízes da delonga na tentativa da tentativa. saberias as longas pestes nos buracos negros dos continentes onde a matéria se arrasta e parte de uma partida fusca e ofuscada como só a partida se sabe por dentro dela própria voltando ao seu início de partida quebrada. é a questão dos cimos e suas voltas torcidas às correntes do horizonte que comanda em filas milimétricas - ao observar o embuste descobres o animal ferido por entre as candeias às avessas que se fecham sobre o pano quando a peça acaba e as cadeiras rangem de medo ao vazio do olhar. não se sabe a certeza que os ventos trazem quando o sexto elemento vem e por entre as tuas fracturas cozidas por um fio rebola. talvez não haja vestes da horas que te tecem. ou as vestes se dispam ao entrar do horizonte de mel e sal por entre a entrada triunfal da orquestra de ossos. sentinela na luz. O Cosmos ou a Caligrafia. (Pereira, 2007: 37). voz autoral do indivíduo medida de si mesma/o, o seu temor é legítimo, tanto quanto a coragem da poeta ao expor as bifurcações, as longas horas de espera, a recusa activa a uma poesia que se quer apartada do social: "O perigo da armadilha é real na medida em que, como criação que produz a miragem do discurso autónomo, a poesia pretendeu ser muitas vezes uma coisa à parte, quando afi nal participa da imanência do social" (Eftekhari, 1997: 55).

o Cosmos ou a Caligrafia. A possibilidade de uma resposta é engendrada pela própria impossibilidade, ou seja é a experiência do impossível que cria a possibilidade. A infinidade do Cosmos e a concretude da Caligrafia, que se quer acção. É no convívio com abismos e fragilidades que Ana se vai construindo num auto-identificar-se-consigo-emoutros-corpos:

Digo que não sou o Alpha nem o Ómega nem qualquer coisa de intermédio. Sou a vocação de minha própria vontade. Sou a minha própria trindade. A sempre possibilidade. Digo que sou uma valência do futuro e o meu corpo aberto há-de ser um dia. Deixai que vos fale do depois. Eu era uma balança de espinhos, uma bifurcação e, por dentro um murmúrio, uma mimosa de espanto. É certo que a arquitectura se espera por dentro, como os dilúvios e quando não existe água, é-se um náufrago em terra - pensava eu. Mas é preciso saber caminhar pela sofreguidão sem nunca inclinar os passos. Digo da sina de esperar as épocas abismadas. Digo do ápice da vontade entreaberta. Sei da seiva que escorre pelas veias e de como se limita a fabricação do arroubamento. Sei da utilidade das diásporas da pele, por onde antevejo o clarão dos sinais decalcáveis. Sei do início sem começo e das cidades imaginárias da memória. Sei dos princípios desfiados e das horas nascentes por dentro dos passos. Digo que dirijo a música aberta dos dedos e nunca questiono o entrançar dos acordes. Digo que sou o sangue pela garganta e as plantações ébrias de futuros. Digo que sou o tremor dentro da terra do desejo e quase nunca pergunto pelo tempo. Não me penteio por não me saber os cabelos de cor. E disso dou graças. Porque sou o eterno chamamento da luz. Escancarada (Pereira, 2007: 55).

"Digo que sou uma valência do futuro". Ana é devir. "Sei dos princípios desfiados e das horas nascentes por dentro dos passos". Entrecortar que desestabiliza a centralidade. Vivência. Tacto. "Digo que sou o tremor dentro da terra do desejo e quase nunca pergunto pelo tempo". Ambiguidades e subtilezas. "Sei da utilidade das diásporas da pele, por onde antevejo o clarão dos sinais decalcáveis". Passo a passo Ana vai des-construindo-se ao mesmo que se constrói.

Na sofreguidão, na inclinação dos passos, no "ápice da vontade entreaberta", ao romper com convencionalismos e a lógica causal, insere a delicadeza do que não é dito, mas que fi 
ca explícito: "Será provavelmente nos interstícios da lógica causal e sequencial com que nos habituamos a pensar o mundo (...) que a possibilidade da abertura existe" (Capinha, 1997:72). Num EXCEDER-se a si mesma: "Escancarada ", é junto ao não-limite, ao lugar que nunca pode ser apreensível pelo olhar totalizante que somos convidadas/os a repensar com Ana Bê, nosso próprio quefazer colectivo e nossa sempre possibilidade.

Ana ao forçar nossos limites (com os quais pensamos e vemos o mundo) nos questiona também: quais são os limites que estipulam na compreensão do corpo nossas experiências? E a ciência? Será que existe nela algo que nos cerceia?

\section{Exceder o corpo e a experiência}

\section{Ana Bê}

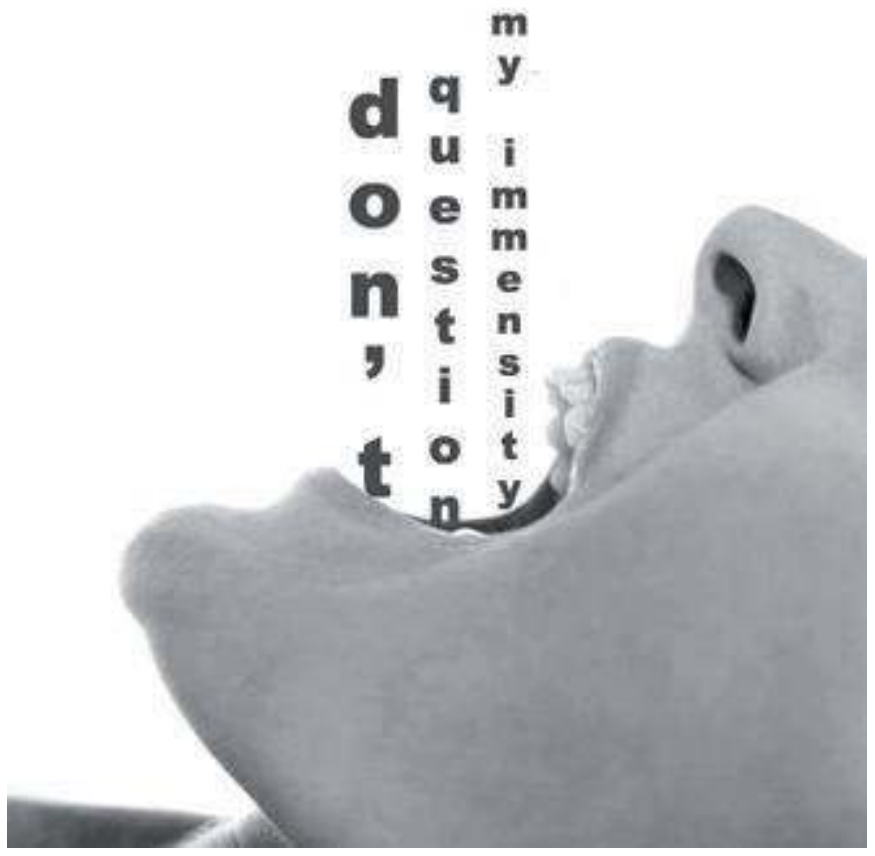

24 A imensidão de um corpo é um impalpável ângulo zero. A poesia de Ana concorda: não se questionam imensidões. $O$ corpo é uma amplidão ininteligível quando buscado a olho nu, por meio de qualquer interpretação totalizante. Só nos aproximamos do corpo e de seus sentidos, quando não questionamos seu existir em instântaneos, seu se dar em relação e nos acostumamos à ideia do fragmento. Para a poesia de Ana o corpo é o deleite do que se excede. O corpo é amplidão. Fragmento. Paradoxo. Compartilhamento. Uma casca sensível. Casca-pele-poro que se intercomunica entre as imensidões. 0 corpo é o dentrofora-dentro em movimento contínuo. "Um cântico incandescente" (Pereira, 2007:45):

quando na noite havia uma azenha

Na desordem olfactiva da luz implacável

Ou o mármore de um baixo relevo numa tapeçaria de linho

E os sítios onde os ossos se despojam

Reconhecendo as tatuagens na voz

Para além da superfície de coágulos que e-

Mana

Na primeira passagem de qualquer litoral

Um poro era uma armadilha penosa 
Uma coincidência de vários horizontes ou a busca

Um poro não se acende por vontade

Espera-se no esforço trémulo ao soletrar os movimentos do

Painel onde se inscreve a brevidade

Um poro espelha-se para se outrifi car

Um poro escoa-se pelas varandas das terras

Um poro expande-se para além da maresia

Um poro pendura-se a secar como uma lágrima

Um poro quer-se de uma paz arrebatada

A um poro quer-se as sementes pinceladas de cinza

A um poro a união dos factos

Nas aberturas dóceis onde fl utuam os pesos

Quer-se de um poro o propósito despojado das unhas descalças

Quer-se de um poro uma acrobata de janelas sem vidros

E as manhãs contidas

De um poro essa clemência anis de madrugadas

Pede-se de um poro a fábula das vivências abrigadas (Pereira, 2007: 46)

A experiência, que só faz sentido acontecendo no mundo e com o mundo, é mais ampla do que qualquer apreensão imediata pode sondar. "Um poro era uma armadilha penosa. Uma coincidência de vários horizontes ou a busca". É uma imagem instantânea, um jogo emblemático que expõe paradoxos: "Um poro espelha-se para se outrificar". O corpo colectivo, exigência primordial do sujeito-com-outras/os. "Quer-se de um poro o propósito despojado das unhas descalças. Quer-se de um poro uma acrobata de janelas sem vidros". Como nomear, algo que se dá sempre-fragmento? A vivência ela mesmo existência.

As cicatrizes da casca. A protecção. "Pede-se de um poro a fábula das vivências abrigadas" (Idem: 46).

O corpo-movimento, concretamente descrito no texto de Ana, culturalmente inscrito e historicamente localizado se aproxima à definição de Latour: "O corpo é, portanto, não a morada provisória de algo de superior - uma alma imortal, o universal, o pensamento mas aquilo que deixa uma trajectória dinâmica através da qual aprendemos a registrar e a ser sensíveis àquilo de que é feito o mundo" (Latour, 2009: 76).

o poro e suas comunicações, suas torrentes de sensações e seu arrebatamento. Novamente Latour nos dá uma pista, sobre como compreender tal vivência: "As partes do corpo, portanto, são adquiridas progressivamente ao mesmo tempo que as "contrapartidas do mundo" vão sendo registradas de nova forma. Adquirir um corpo é um empreendimento progressivo que produz simultaneamente um meio sensorial e um mundo sensível" (Idem: 76).

o dentro-fora do corpo se expande em vivência sensorial e sensível, memória e possibilidade: "Digo que os dias são matrizes palpáveis de memória, como a substância indizível do mel e que as rotas se abrem por dentro, como um ninho de pequenos louvores. Era um aguçado lugar falível mas preenchido de graça. Eu era a possibilidade e disso dou conta. Por dentro da voz" (Pereira, 2007: 54).

Um corpo dentro-fora, que se outrifi ca, tecido em meio a incompletudes e questionamentos, que interroga concepções sedimentadas e sesgadas: "E é certo que, nas sociedades Ocidentais, os níveis de participação, contribuição e produção estão adaptados a um paradigma desejável de um corpo e mente saudáveis, fortes e sem limites - no fundo o paradigma desejado pelo capitalismo e pelo modelo neo-liberal" (Pereira, 2008: 48). 
31 Um paradigma que, aliás, não é negociável conforme afirma: “O problema é que a sociedade Ocidental não negoceia a forma como cada um(a) pode contribuir de acordo com a sua incapacidade" (Idem: 49 ).

Deslindando o interesse e consequente investimento das práticas capitalistas em concepções estáveis e fixas de corpos e identidades e a persistente recusa em lidar com as diferenças, Ana propõe olharmos o corpo desde uma perspectiva política ou, como sugere o antropólogo Miguel Vale de Almeida a partir de uma «política do corpo» que, se ainda não conta com um desenvolvimento pleno na Academia, tem vindo a reclamar crescentemente a atenção desde práticas situadas:

O corpo é um exemplo de um objecto de outro tipo: um objecto que é também sujeito. Ele é o interface perfeito entre natureza e cultura, entre indivíduo e sociedade, entre autonomia e regulação. Muitos seriam os exemplos possíveis, mas talvez o mais relevante para pensar politicamente seja o que tem a ver com a questão da incorporação: o corpo como interiorização não verbal, inconsciente, mimética, automática, de certas disposições de desigualdade e poder; mas não só como interiorização - também como reprodutor dessas realidades, seu confirmador constante pelo facto simples de estar lá, de aparecer, de ser. É neste nível micro, quase imperceptível, da incorporação dos esquemas de diferença e desigualdade, que se joga uma política de baixa intensidade, uma micropolítica de difícil intervenção por parte da usual macropolítica. É a política do face a face, do encontro casual de rua, da visibilidade confirmadora do que nos rodeia (Almeida, 2004: 12-13).

Compreendendo o corpo em sua materialidade apreensível (e inapreensível) e as micropolíticas que o conformam, ele aparece na prosa e poética de Ana Bê como um lugar falível, mas preenchido de graça. Corpo colectivo, fortalecido pela luta. Re-significado, revisitado, redimensionado:

Questionar o mito super-humano e admitir a fragilidade do nosso corpo não nos torna mais vulneráveis, pelo contrário, torna-nos mais fortes e mais equipadas para lidar com a adversidade e a dificuldade inerentes à nossa condição humana. $\mathrm{O}$ facto de nos ausentarmos desta parte de nós significa que não valorizamos nem recolhemos os conhecimentos do mundo que lidam com a doença e com a dor (Pereira, 2008: 94).

Corpo que só pode ser apreendido por sua constante ambivalência, partindo de uma definição mais ampla, que não ignora a dor, mas sim a incorpora como uma forma epistêmica legítima, de si, das/os outras/os e do mundo. E, que também não é somente constatação empírica, porque a dor faz parte também de um compartilhamento, de um vivenciar da/o-outra/o, aquilo que se concebe em e através das relações:

Proponho por isso um conceito de saúde e de doença não dicotómico que conceptualize os dois como elementos entrelaçados daquilo a que chamaria uma tapeçaria do ser continuamente em construção. Esta tapeçaria integra em si padrões que ora podem ser variados, ligeiramente diferentes ou mesmo contrastantes, por vezes um padrão será mais acentuado que outro, de outras, novos padrões até aí inexistentes começam a formar-se. Desta tapeçaria fazem parte ainda cores ou linhas que podem variar ao longo da tecedura e ainda pontos que diferem entre si e certamente espaços deixados por preencher assim como retalhos aproveitados ao acaso, no entanto TODOS estes elementos fazem parte do mesmo constituinte que não corresponde a uma unidade unificada mas que exala na beleza da sua imperfeição. A corporalidade humana e a sua relação com o que edificamos como saúde e doença será assim uma entidade em construtura constante, com cortes, roturas e intromissões (Pereira, 2008: 94). 
Corpo-não-totalidade, mas movimento, um tomar parte: "E agora os corpos permeáveis apenas pelo não-saber [E-terno vul nerável] nada restando dos resíduos empíricos do experiência mento Agora dura doiro e Encarnado a pele de rosáceas estendidasostensivas marcando O OUTRO a presença o pisar constante dos mesmos trilhos (...)" (Pereira, 2007: 22).

A proposta teórica de Ana Bê que re-signifi ca a dicotomia clássica entre saúde e doença, dispondo-as tecidas em uma "tapeçaria do ser continuamente em construção" (Pereira, 2008: 94), em consonância com sua proposta poética, utiliza-se das vulnerabilidades para fortalecer, colectivamente sujeitos reposicionados em novas formas de colaborações e "experiência mento". Tal como provoca a feminista Susan Bordo (2001: 78): "Sem imaginações (ou o engajamento com o corpo) da alteridade, desde que ponto de vista, podemos buscar a transformação da cultura? E como construíremos estas imaginações e engajamento com o corpo, se não através de uma aliança com o que foi silenciado, reprimido e desdenhado"? Ana nos conta que uma ciência engajada e comprometida necessita de alianças instáveis, parciais e contra-hegemónicas para responder ao silenciamento e à opressão.

E, talvez, aqui esteja uma das maiores e mais lúcidas contribuições de Ana e sua poesia para alargarmos o conceito de corpo, para as práticas e estudos feministas, em nossos trabalhos e na ciência engajada que buscamos construir: o corpo não é apenas experiência empírica, a própria experiência não é apenas empírica, ela se dá-dando em relação, um conhecimento compartilhado e solidário de amplitudes e presenças, mas também de ausências e assombros. Enfim, o corpo exige uma política do corpo, porque é tessitura, aliança e imaginação. Não se restringe a mim, sujeito individual, mas se realiza e é realizada na convivência com outros corpos.

Corpo é experiência em relação quando EXCEDE o limite entre o que sou eu, empiricamente falando, e o que é a/o outra/o. O que é o mundo e como dele nos aproximamos:

o corpo é essencial para o entendimento que temos do mundo. Muitas vezes relacionamo-nos com o mundo através de configurações corporais materializadas através da linguagem, como por exemplo quando dizemos "a perna da mesa", "ter mão em alguma coisa", "a barriga da perna", "ter um pé-demeia", "estar ao pé de" ou "levar alguma coisa a peito". Nesta relação metonímica com o mundo-corpo, o exterior torna-se uma extensão do corpo-mundo. (Pereira, 2008: 176).

A escrita de Ana não questiona a imensidão de nossas vivências, contextualizando-as histórica e materialmente, apenas as tece conjuntamente, lidando com os paradoxos, sem buscar categorizá-los, cindi-los. "Uma relação metonímica com o mundo-corpo". Seu posicionamento político, crítico e académico é antes de tudo anti-categorial, corroborando Miguel Vale de Almeida quando este descreve o caminho de uma possível «política do corpo»:

A verdade é que em todos estes aspectos em que o corpo fala de modo ventríloquo das relações sociais, não só é fulcral a educação para a diversidade, a igualdade e a individualidade - uma educação anti-categorial e anti-categórica - como é fundamental o estímulo à produção cultural e de representações alternativas, que criem um mundo de diversidades estilhaçadoras de categorias (Almeida, 2004: 17).

Expurgar o fragmento, a diversidade, a empatia, a vivência colectiva que se sente sob a pele sem saber muito bem explicar porquê, seria reducionista, um ocultamento proposital, um silenciamento simplista. Seria conviver com e admitir que para além da moldura não existe vida. A poesia de Ana não concebe uma luta que não seja integral, que 
não seja ela mesma extensão: para se reler o corpo, é preciso irmos também para além do eu. É necessário situá-lo como fundamento e centralidade de uma luta política que almeja transformações nas relações de poder desiguais que vivenciamos. Como Vale de Almeida sublinha: "O corpo manifesta-se, faz o seu próprio manifesto. Nas doenças, nos êxtases, nas depressões, nas manipulações de que é alvo, no amor, numa mudança de sexo, numa dança, numa greve de fome. 0 corpo pede política, e da emancipatória" (Almeida, 2004: 17). É essa política emancipatória que o trabalho de Ana Bê persegue ao desestabilizar e baralhar os limites consensuados entre o que compreendemos como saúde e doença, os limites de concepções como aquelas que, mesmo dizendo-se neutras, distinguem hierarquicamente entre o corpo considerado capaz e o corpo in-capaz.

41 As propostas teórica-poéticas de Ana Bê, ao privilegiar a tessitura, as fissuras, "cortes, roturas e intromissões", movem-se em direcção às intersecções. São nessas intersecções e nos interstícios, que um novo corpo também surge, delicado e frágil e, por isso mesmo, mais combativamente colectivo, preparado para lidar com o inconstante, com o novo e com o imprevisível.

\section{Ciência(s), feminismos e a questão da linguagem na poesia contemporánea}

nos ALICERCES materiais a pá ciência afoga espécies inventa contrastes e nos órgãos céu-lulas um íntimo pendurado ao limite quase interlúdio de cinzas escamadas (Pereira, 2007: 14)

Crítica, a poesia e a escrita de Ana é sobretudo lúcida: consciente dos encobrimentos e da cumplicidade da Ciência (com "C" maiúsculo) na criação de um certo "tipo" de mulheres, homens e hábitos seu objectivo é questionar os alicerces de uma Ciência que sufoca saberes, num jogo acirrado em que relações de poder instituem e destituem conhecimentos, hierarquizando práticas e mutilando, por meio de discursos herméticos, a diversidade das experiências do mundo:

enfim, numa mera sucessão angustiante de premissas aparentemente reveladoras mas que numa segunda reflexão de configurações significativas se revelaram absolutamente inócuas à materialização das conotações psicossomáticas naquele que era de facto um contexto metafísico-epistemológico de conclusões duvidosas embora fosse claro que a interacção de fatores era um facto e não poderia já ser suplantada pela mínima intervenção ou tentativa de reversibilidade. (Pereira, 2007: 26)

A Ciência hegemónica, de "premissas aparentemente reveladoras", ancorada numa ordem do discurso cifrado e inacessível, não suporta um escrutínio crítico: o conteúdo - de tal conhecimento pomposo - baseado num jogo de palavras rebuscadas se revela "absolutamente inócuo", ou seja, não tem efeito. Embora admita Ana Bê que exista matéria-prima para reflexão - "a interacção de fatores era um facto" -, as conclusões, fechadas em si mesmas, só podem ser duvidosas.

A poesia brinca com jargões técnicos, o discurso científico hegemónico, embora possua ambições universalizantes e generalizantes, embala-se em enunciados reducionistas. Revelando-se a comicidade da erudição talhada em vocabulários herdeiros do Iluminismo, de pressupostos filosóficos eurocêntricos, as palavras mais distanciam do que aproximam sujeitos e conhecimentos. A linguagem hermética e de cariz puramente disciplinar é o meio que a Ciência utiliza para hierarquizar e, às vezes, invisibilizar conhecimentos, 
sujeitos e lutas sociais. O conhecimento, nesse caso, pertence a quem tem o monopólio sobre o discurso-linguagem:

o processo visou refutar através da ambivalência caracteristicamente doutrinal independentemente de processos materiais feitos conjuntamente através da implantação de feiticização de dimensão espacial ou mesmo lutas simbólicas estigmatizadas pela dimensão da conjuntura particular de diapositivos que remetem para uma visão foucaultiana que tornaria implícita a noção de objectivo ou seja numa lógica normalizadora o poder-cósmico contrapõe-se de forma intensa à incidência dos denominados micro-factores que maximizados fundamentam na opinião daquele um tratamento de monopólio face à heterogeneidade que encerra a incorporação do mundo actual. não sei se me faço entender. (Pereira, 2007: 26) poeta Charles Bernstein (1997) denomina "políticas da linguagem". A poesia de Ana manifesta que existe uma política da linguagem dominante presente nos textos científicos-académicos, por meio da qual uma erudição descolada da realidade tem o poder-monopólio de subsumir não apenas "lutas simbólicas estigmatizadas", retirandolhes o sentido, a contextualização e a historicidade, mas também submetendo-as a "uma lógica normalizadora", reduzindo-as a puro texto, texto esse que, por sua vez, perde-se em derivas abstractas. Mesmo as narrativas emancipatórias têm sua materialidade expurgada, a fim de que não perturbem o jogo incompreensível de certas convenções consensuais no meio científico.

A sátira-sopa-de-letrinhas a qual Ana Bê utiliza, demonstra com contundência os limites que certa padronização inflexível representa para a construção de novas formas de relação entre quem monopoliza a construção do suposto conhecimento científico e os sujeitos do conhecimento propriamente ditos, ou como diria Charles Bernstein: “... em muitos casos, certos detalhes (matéria concreta ou factos sociais) não são passíveis de articulação através das convenções linguísticas dominantes" (Bernstein, 1997: 111). EXCEDEndo a tessitura do texto-texto para articulá-lo com o texto-vida, Ana Bê rompe com a linguagem abstracta, descorporificada e não-localizável para denunciar a cumplicidade da linguagem dominante com o projeto moderno de colonização da vida a partir de pressupostos eurocêntricos erigidos sobre a superioridade fictícia do homem branco, heterossexual e ocidental (Bordo, 2000; Haraway, 1995; Pereira, 2008).

47 A poesia de Ana Bê mais uma vez escancara a complexa arquitectura da exclusão: para além de uma ideia que contempla apenas corpos perfeitos e capacitados, para além das invisibilidades, existe também uma exclusão latente e explícita na ordem do discurso científico. Uma espécie de moldura-outra, que funciona como barreira e trincheira: dividindo quem "fala a mesma língua" de quem não a compreende.

Ao ironizar a linguagem científica que não dialoga com suas/eus outras/ os ${ }^{6}$, Ana Bê não só rompe com a ideia de uma hegemonia discursiva pairando como um ente etéreo e transcendente - como nos faria crer alguns pós-estruturalistas ${ }^{7}$ - como também desvela uma dimensão que se quer ausente, porque se pretende neutra e objectiva: a materialidade das práticas sociais de exclusão travestidas em discurso hermético, classificatório, universalizante e opressor. A ordem e o poder hegemónico expressos por meio da linguagem "era de facto um contexto metafísico-epistemológico", não apenas um limite discursivo imposto para diferenciar, doutrinar ou adestrar iniciadas/os e nãoiniciadas/os, a linguagem funciona aqui, de acordo com a poesia, como geradora de hierarquias, que encarnam e perpetuam discriminações, tentando emudecer e apagar resistências e enfrentamentos. 
49 Os limites da linguagem científica, seus usos e abusos, seu caráter racista, sexista, classista, falocêntrico e solipsista desde muito tem sido denunciado pelo trabalho sério e comprometido de autoras e autores preocupadas/os com as invisibilizações e ocultamentos políticos, históricos e sociais presentes nas "políticas da linguagem". Contudo, têm sido os feminismos e sua complexa teoria cultural que têm vindo mais consistentemente a analisar as intricadas tramas e articulações presentes numa linguagem aparentemente neutra e universalista (Hooks, 2004; Morales, 2004; Morrison et al., 1993).

Como afirma a escritora feminista Toni Morrison, em seu discurso na cerimónia em que foi laureada com o prémio Nobel de Literatura:

A linguagem opressora, mais que representar a violência é violência; mais do que representar os limites do conhecimento limita o conhecimento (...) - seja a linguagem orgulhosa e calcificada da Academia ou a mercadoria orientada à linguagem da ciência; a língua maligna da lei-sem-ética, ou uma linguagem projectada para o distanciamento das minorias, escondendo sua pilhagem racista na retórica - [essa linguagem] deve ser rejeitada, alterada e exposta. É a linguagem que bebe sangue, regozija-se com vulnerabilidades, chafurdando suas botas fascistas em criolina, respeitabilidade e patriotismo, enquanto se move implacavelmente em direção à linha de fundo e ao fundo da mente. Linguagens sexistas, linguagens racistas, linguagens teístas: todas são típicas representações do policiamento, do domínio e não permitem novos conhecimentos nem incentivam o intercâmbio de ideias $^{8}$ (Morrison, 1993).

51 Em sua fala contundente ,Toni Morrison torna evidente o papel específico e cúmplice que a linguagem desempenha em certas práticas sociais. Numa perspectiva, talvez menos contundente, mas também veemente, quando fala sobre sujeitos nómadas, novas articulações e transformações reais e históricas que acabaram por deslocar a ideia de uma identidade hegemónica, unitária e essencial, Rosi Braidotti é enfática ao assinalar a contribuição da teoria feminista para repensarmos a linguagem e a necessidade da criação de espaços onde possamos pensar de modo diferente:

Identidade múltipla, mutável e em contradição consigo mesma. (...) O sujeito não está dividido pela linguagem e sim em discordância com ela. As feministas propuseram que a racionalidade não constitui a totalidade da razão e que a razão não abarca a totalidade - e nem sequer o melhor - da capacidade humana de pensar.

Em consequência recusaram a equação entre o ser e a linguagem logocêntrica. A teoria feminista constitui a crítica ao poder no discurso e como discurso, e o esforço activo para criar outras formas de pensamento; ou seja, o compromisso com o processo de aprender a pensar de modo diferente (Braidotti, 2004: 22).

52 Ana, desse modo, torna manifesto em sua escrita, o que outras militantes orgânicas e académicas feministas, como Aurora Morales, expunham em seus trabalhos: "Utiliza-se a linguagem desnecessariamente especializada para humilhar a quem se supõe não autorizado para entendê-la. Vende-se a ilusão de que somente quem a sabe manejar é capaz de pensar" (Morales, 2004: 68). Esta intelectual feminista continua:

Uma resposta frequente para quem mostra resistência a essa linguagem exclusiva é que sofrem de cansaço intelectual. Como qualquer outra forma de controlar as entradas, o caso é que nós, e não as portas, somos as responsáveis por tê-las atravessado. Devemos abandonar o que estamos fazendo, esquecer o motivo pelo qual viemos e dedicar nossas energias a aprender as técnicas de invasão de endereço. (Morales, 2004: 69) 
53

$$
\begin{aligned}
& \text { articuladora de um amplo projecto que desqualifica e exclui. Nesse projecto a Ciência, tal } \\
& \text { qual a linguagem, cria nuances variadas e amplia seu escopo para além dos muros } \\
& \text { universitários, formando e formatando pessoas para actuarem dentro de regras- } \\
& \text { molduras, como também vaticina Toni Morrison: } \\
& \text { É e será (...) uma linguagem que arma e mantém armadas/os as/os cidadãs/os; } \\
& \text { massacrando-as/os em shoppings, tribunais, correios, parques infantis, quartos e } \\
& \text { avenidas; memorizando fórmulas para mascarar a pena e o desperdício de uma } \\
& \text { morte desnecessária. Haverá uma linguagem mais diplomática para aprovar o } \\
& \text { estupro, a tortura, o assassinato. Haverá uma linguagem mais sedutora, mutante e } \\
& \text { dinâmica projectada para estrangular as mulheres, para triturar suas palavras } \\
& \text { transgressivas, como foie-gras em suas próprias gargantas, não permitindo-as falar } \\
& \text { do indizível; haverá muito mais da linguagem da vigilância disfarçada de pesquisa; } \\
& \text { de política e história calculados para emudecer o sofrimento de milhões; linguagem } \\
& \text { glamourosa para emocionar os insatisfeitos que em privado agridem suas/eus } \\
& \text { vizinhas/os; linguagem arrogante pseudo-empírica usada para prender pessoas } \\
& \text { criativas em gaiolas de inferioridade e desesperança (Morrison, 1993). }
\end{aligned}
$$

Uma Ciência irresponsável e não-democrática, que, além de não cumprir seu papel, é

É contra esse tipo de Ciência e linguagem, hegemónicas, canónicas e alicerçadas em preconceitos que a escrita de Ana se insurge. Essa Ciência e essa linguagem que pregam supostas neutralidades que sua poesia já nos demonstrou serem impossíveis e cínicas.

É por isso que, tal como outras intelectuais feministas, Ana busca novas formas para expressar-se e expressar sua luta: “A linguagem está ligada ao conteúdo, e o conteúdo que eu busco é uma teoria e uma prática intelectual

que me resulte útil numa pesquisa activista, cujas prioridades são, sobretudo,

democratizadoras." (Ibidem: 69), parece dizer em coro com Morales (2004). E,

continua, buscando como Morrison (1993):

[que] Seja [uma linguagem] explosiva, que se recuse a santificar-se; que se ria em voz alta ou seja um grito sem alfabeto, a escolha das palavras, o silêncio que escolhe, línguas nativas que surgem em direção ao conhecimento, e não em direção à sua destruição. Quem nunca ouviu falar de uma literatura banida porque é interrogativa? Desacreditada porque é crítica? Apagada porque alternativa? (Morrison, 1993).

Experimentações que não sejam reféns das convenções, mas antes desafiem o statu quo, as normatizações impostas, os falsos consensos, mesmo correndo o risco do banimento, do equívoco, da crítica rasa, das interpretações mal-intencionadas:

\section{Epílogo}

Poesia-posicionada que proporciona a cada uma/um de nós um percurso diferente: revirando do avesso certas concepções e caminhando por lugares pouco palatáveis e acolhedores, como muitas vezes é pouco palatável e acolhedor o nosso turbilhão interno, não é apenas na crítica ao capacitismo Ocidental, à Ciência, à linguagem científica e suas/ eus Outras/os que Ana sustenta sua narrativa.

Ultrapassando o limite da crítica fácil e das soluções prontas, alguns poemas parecem nos indagar sobre a fluidez de nossas identidades, a fragmentação das outrora estáveis categorias de sexo, género, classe, local de nascimento, orientação sexual, geração, expondo a delicada - e cambaleante - relação existente entre identificação, 
representação, hegemonia e poder. Ana parece provocar-nos, questionando por que nos deveríamos localizar numa identidade se todas elas são produzidas pelo poder. No trecho seguinte, essa ideia, que brinca com os estereótipos, é vista e revista a partir de um jogo que conjuga a experimentação estética com a perspicácia intuitiva das performances identitárias, amplificando indagações, desestabilizando linearidades e ironizando a fixidez: "As Putas é que têm sorte - disse ela - gritando estridente mãos pendendo assim" (Pereira, 2007: 27), mas não é tudo, já que em ERRATA - ao fi m do livro - é possível reler o mesmo poema, agora orientadas/os pela autora: "Página 27 - Onde se lê «as putas» deve-se ler «os putos ${ }^{9} » "($ Pereira, 2007: 58).

62 Ana demonstra que aqui o que está delicadamente em jogo é uma ideia de "mulher" essencial, forjada por relações patriarcais, que ao privilegiarem o homem branco, ocidental, heterossexual, como sujeito e relegar aos Outras/osoutras/ os espaçosfigurações, sejam elas/es mulheres, Putas ou putos, ignoraram que as identidades, em realidade, são posições de sujeito fluídas e intercambiáveis abertas a um constante reposicionar-se. Ao sugerir uma inversão na leitura linear do poema, Ana brinca com o próprio lugar de enunciação. Será Ana quem grita e pende as mãos? Ou ela é uma testemunha no jogo performático de nomeação e desvelamento? Ao continuar o poema, com as Putas e/ou os "putos", Ana Bê se interroga e se rebela: "Mas não uma história isto é. Isto é, poderia ser. Os turbilhões revoltam-se em escamas intensas também os ossos." (Pereira, 2007: 27). A história, como a linguagem, ou a ciência, não está pronta, tal qual o corpo, ela é relação, vir-a-ser, movimento. Um convite:

além do delito do delírio/ passou à dependência do mar partilhando os seus hábitos/ engolindo pessoas ocasionalmente/ passou a ser contígua à passagem e à efusão juntas/ esgotava a divisão em saltos acrobáticos/ que desafiavam o tecto/ nunca vira a solidificação transitória dos objectos não-suspensos/ talvez não soubesse como habitar os turnos semi-luzidios das horas/vivia além dos traços que se rodeavam de outros/ era tão brusca a sua solidez/ despenhava-se por conhecer a mudez aberta dos gestos/ incorporava o espaço/ de cada vez que o silêncio se tornava demasiado esbranquiçado/ não era antiga a sua tremenda ressureição/ era antes esculpida na curva de um granito de idade indeterminada (Pereira, 2007: 32).

63 A narrativa linear é perturbada por outros pontos de vista, informada pelos feminismos e pelas diversas maneiras de resistirmos e de enfrentarmos as opressões a que somos submetidas/os. Apesar de inscrever as relações patriarcais em sua poesia, Ana sabe que a construção da verdade narrativa nem sempre tem raízes na verdade histórica e, por isso, brinca e re-cria "nas dobras das nódoas figurações pós-qualquer-coisa pós traço qualquer traço coisa", um espaço novo que pode muito bem ser habitado por "todos os fenómenos de vimculação" (Pereira, 2007: 27) e responder, intensa e activamente, aos turbilhões que nos chegam até aos ossos. Des-construindo géneros, relações hierárquicas, preconceitos. Excedendo os seus limites e nos convidando, a todas e todos nós, a excedermos também nossas semânticas para além das bordas e das fronteiras. 


\section{BIBLIOGRAPHY}

ALMEIDA, Miguel Vale de (2004), “O manifesto do corpo”, Revista Manifesto, no 5; 17-35.

BEAUVOIR, Simone (1984), Le Deuxième Sexe. Les faits et les mythes. Paris: Gallimard.

BERNSTEIN, Charles (1997), “A-poética” Revista Crítica de Ciências Sociais, 47; 101-122.

BORDO, Susan (2001), "El feminismo, la cultura occidental y el cuerpo", La Ventana, 14; 7-81.

BORDO, Susan (2000), “A feminista como o Outro”, Revista Estudos Feministas, 8; 10-29.

BRAIDOTTI, Rosi (2004), Feminismo, diferencia sexual y subjetividad nómada. Barcelona: Gedisa.

CAPINHA, Graça (1997), “Tecendo e distorcendo o colonialismo da linguagem: um pequeno e cotidiano exercício de poética”, Revista Crítica de Ciências Sociais, 47; 65-73.

EFTEKHARI, Pirouz (1997), "Poeticidade e poesia”, Revista Crítica de Ciências Sociais, 47; 55-64.

GALCERÁN, Montserrat (2009), Deseo (y) libertad: Una investigación sobre los presupuestos de la acción colectiva. Madrid: Traficantes de Sueños, série Mapas, $1^{\text {a }}$. Edição.

HARAWAY, Donna J. (1995), “Saberes localizados: a questão da ciência para o feminismo e o privilégio da perspectiva parcial", Cadernos Pagu, 5; 7-41.

HOOKS, Bell (2004), “Mujeres negras: dar forma a la teoría feminista”, in B. Hooks et al.(Eds.) Otras inapropiables: feminismos desde las fronteras. Tradução Rocío Macho Ronco et al. Madrid: Trafi cantes de Sueños, pp. 33-50.

LATOUR, Bruno (2009) “Como falar do corpo? A dimensão normativa dos estudos sobre a ciência”, in J. A. Nunes e R. Roque (Orgs.) Objectos Impuros: Experiências em Estudos sobre a Ciência. Porto: Edições Afrontamento.

MORALES, Aurola Levins (2004), "Intelectual orgânica certifi cada”, in B. Hooks et al.(Orgs.) Otras inapropiables: feminismos desde las fronteras. Tradução Rocío Macho Ronco et al. Madrid: Traficantes de Sueños, pp. $63-70$.

MORRISON, Toni (2012), Nobel Lecture in December 7, 1993. Documento disponível em: http:// www.nobelprize.org/nobel_prizes/literature/laureates/1993/morrison-lecture.html.

PEREIRA, Ana Maria Baila Albergaria (2008), Viagem ao interior da sombra: deficiência, doença crónica e invisibilidade em uma sociedade capacitista, Dissertação de Mestrado em Sociologia: PósColonialismos e Cidadania Global, Faculdade de Economia e Centro de Estudos Sociais, Universidade de Coimbra.

PEREIRA BÊ, Ana (2007), As patas posteriores das pulgas. Coimbra: Edição da autora, 1ª Edição.

SANTOS, Boaventura de Sousa (2002), "Para uma sociologia das ausências e uma sociologia das emergências", Revista Crítica de Ciências Sociais, 63; 237-280.

PEREIRA, Ana Bê. Sítio na Universidade de Lancaster: http://www.lancs.ac.uk/fass/centres/gws/ pgrprofi les/437/ [Consultado em 20 de Outubro de 2012].

PEREIRA, Ana Bê. Sítio Pessoal: http://www.anabeonline.com/ [consultado em 20 de Outubro de 2012]. 
PEREIRA, Ana Bê. Sítio Academia.edu http://lancaster.academia.edu/AnaB\%C3\%AA/ [consultado em 20 de Outubro de 2012].

PEREIRA, Ana Bê. Sítio de Poesia: http://www.ana-b.com/ [consultado em 20 de Outubro de 2012].

\section{NOTES}

1. Título emprestado de "Génios", poema disponível em: http://www.ana-b.com/genios.html (consultado em 20 de Outubro de 2012).

2. "Há produção de não-existência sempre que uma dada entidade é desqualifi cada e tornada invisível, ininteligível ou descartável de um modo irreversível” (Santos, 2002: 245).

3. Para um conceito abrangente sobre os conhecimentos situados e a objectividade incorporada e suas contribuições à teoria feminista ver sobretudo: Haraway 1995).

4. A "Oficina de Poesia" é um curso-livre (semestral) da Faculdade de Letras da Universidade de Coimbra, com o apoio do Centro de Estudos Sociais, coordenado por Graça Capinha: "Neste curso, o discurso poético é entendido como um marginalizado discurso do conhecimento e como uma prática de cidadania: um trabalho de intervenção sobre a linguagem do senso-comum, e uma responsabilidade de interferir na ordem do mundo (sobretudo na ordem do mundo daqueles que nunca foram expostos ao discurso poético). Deste entendimento resultam as leituras públicas e o interesse pela exploração de outras linguagens do saber". Definição da Oficina disponível em: http://www.ces.uc.pt/projectos/novaspoeticas/pages/portugues/oficina-de-poesia.php?lang=PT (Consultado em 20 de Outubro de 2012).

5. Maria Galindo é uma das fundadoras do colectivo feminista boliviano "Mujeres Creando". Disponível em: http://www.mujerescreando.org/ (consultado em 21 de Outubro de 2012).

6. Seguimos para definir a/o "Outra/o" tanto a Simone de Beauvoir (1984) quanto a Susan Bordo (2000). Para estas autoras existe, dentro do mundo social, aquelas/es que ocupam a posição não específica do essencial, universal e humano e aquelas/es outras/os que são reduzidas/os, definidas/os e marcadas/os por sua diferença. Essas/es configuram a/o Outra/o em relação a uma norma pré-estabelecida.

7. É interessante notar como no poema, Ana Bê realiza uma crítica feminista subtil, desnaturalizando a hegemonia sobre a "visão foucaultiana" ao colocá-la ao lado de palavras utilizadas à exaustão nos textos científicos sobre normalização, exclusão e acesso das "lutas simbólicas" ao poder, manifestando, dessa forma, os limites das análises discursivas quando confrontadas com a materialidade presente nas lutas por justiça social e na subsunção da crítica feminista nas análises que privilegiam "a autoria" foucaultiana sobre os regimes de poder-saber. Como assinalou Susan Bordo: "Considere, por exemplo, a concepção de corpo, própria ao século $\mathrm{XX}$, como algo socialmente construído. Tais noções devem muito ao feminismo, não apenas aos escritos académicos feministas, mas ao desafio mais público ao determinismo e ao essencialismo biológicos, cultivado pelo feminismo militante do fi nal dos anos 60 e início dos 70 através das demonstrações, dos manifestos, das sessões de conscientização e dos primeiros escritos populares. No centro da "política pessoal" estava a concepção de corpo como algo profundamente moldado, tanto materialmente quanto em termos de representações, por ideologias culturais e práticas disciplinares. Mas é Foucault quem geralmente recebe os méritos (...) como o pai da "política do corpo»" (Bordo, 2000: 13).

8. Todas as traduções do inglês ao português e do espanhol ao português são de responsabilidade das autoras.

9. Em Portugal, a palavra putos é usada como sinônimo de meninos. 


\section{ABSTRACTS}

São diversos e instigantes os debates sobre a literatura como locus frutífero tanto para a reprodução de discursos misóginos quanto para a criação de novas enunciações femininas/ feministas. Inspirada em tais debates, este artigo pretende elaborar sobre a escrita feminista contemporânea tendo como ponto de partida a obra da poeta portuguesa Ana Bê Pereira. Jovem autora à margem do mercado editorial de grande porte, Ana Bê redimensiona a literatura engajada, conjugando a experimentação estética com o exame minucioso da inserção das mulheres na sociedade, interrogando e re-criando concepções sobre o corpo e a linguagem para extrapolar molduras e limites.

There are several debates about the literature as a fruitful locus, either for the reproduction of misogynous speeches, either for the creation of new feminine/feminist statements. Inspired by such debates, this article intends to elaborate on the contemporary feminist literature, having as a starting point the work of the Portuguese poet Ana B. Pereira. Young as a young writer on the margins of the grand editorial market, Ana B. gives politically engaged literature a completely new dimension, through the combination of aesthetic experimentation with the meticulous examination of women's insertion in society.

Les débats sur la littérature en tant que lieu fécond aussi bien pour la reproduction de discours misogynes que pour la créer de nouvelles thèses de femmes/féministes sont variés et stimulants. Inspiré par de tels débats, cet article propose de disserter sur l'écriture féministe contemporaine en ayant comme point de départ l'oeuvre de la poète portugaise Ana Bê Pereira. Jeune auteur, en marge du marché de la grande l'édition, Ana Bê redimensionne la littérature engagée, en combinant l'expérimentation esthétique avec l'examen minutieux de l'intégration des femmes dans la société et en interrogeant et recréant des conceptions sur le corps et le langage, pour extrapoler des cadres et des limites.

\section{INDEX}

Mots-clés: poésie féministe contemporaine, critique féministe, littérature engagée, corps

Keywords: contemporary feminist poetry, politically engaged literature, body

Palavras-chave: poesia feminista contemporânea, crítica feminista, literatura engajada, corpo

\section{AUTHORS}

\section{LENNITA OLIVEIRA RUGGI}

Socióloga, Professora de Sociologia da Educação na Universidade Federal do Paraná, lennitaruggi@hotmail.com 
ROSIMEIRE BARBOZA SILVA

Psicóloga, doutoranda em Sociologia no Centro de Estudos Sociais da Universidade de Coimbra, Portugal, rose.bs@uol.com.br 